\title{
IN BETWEEN: SOBRE LA INSERCIÓN Y LOS DISEÑOS IDENTITARIOS DE MIGRANTES LATINOAMERICANOS EN NUEVA YORK
}

\author{
In Between: On Insertion and Identity Formation of Latin American Migrants in New York
}

\author{
Juan Carlos Narváez-Gutiérrez
}

Resumen: En el presente artículo se exploran algunos elementos de los que se valen los migrantes latinoamericanos para reconstruir/ deconstruir sus identidades en el contexto de una sociedad huésped: urbana y anglosajona. A través del análisis de las dimensiones de inserción e incorporación objetiva y subjetiva, y con base en fragmentos de entrevistas realizadas en la ciudad de Nueva York, se trata de dejar registro sobre lo concreto y lo interpretativo de la experiencia narrada por los sujetos de la migración internacional.

Palabras clave: migrantes, latinoamericanos, inserción, incorporación, identidades, identificaciones, migración internacional, sociedad huésped.

Abstract: This paper explores some elements that use the Latin American immigrant to reconstruct/deconstruct their identities in the context of a host society: urban and Anglo-Saxon. Through the analysis of the objective and subjective dimensions of insertion and incorporation, and supported by interviews pieces conducted in New York City to immigrants, the text try to put on record on the concrete and the experience interpretative of the immigrants as subjects of the international migration.

Keywords: immigrants, Latin-Americans, insertion, incorporation, identities, identifications, international migration, host society.

Juan Carlos Narváez Gutiérrez, doctor en Ciencias Sociales por la Facultad Latinoamericana de Ciencias Sociales y candidato a doctor por la Universidad de Leiden. Investigador del Centro de Estudios Migratorios de la Unidad de Política Migratoria en la Ciudad de México. Temas de especialización: jóvenes, migración, identidad y cultura transnacional. Correo electrónico: jcnarvaezgutierrez@gmail. com; cnarvaez@inm.gob.mx.
Enviado a dictamen: 11 de abril de 2012

Aprobación: 31 de octubre de 2012 Revisiones: 1 
Introducción: New York iaquí también se habla español!

A diferencia de otras ciudades estadounidenses, de acuerdo con Nancy Foner (2001) Nueva York se constituye históricamente como la gran capital americana de los inmigrantes. Quizá el hecho de haber sido el principal y mayor puerto de entrada de extranjeros durante los siglos pasados ha hecho de la ciudad y su política frente a la inmigración un espacio más abierto, tendente al diálogo y la inclusión, distinguiéndose de otras incluso tan grandes y multiculturales como Los Ángeles. Nueva York, dicen los neoyorquinos, no es EE.UU., es una burbuja rodeada de nación norteamericana (Smith et al., 2001).

A finales del siglo XX, en el periodo que va de 1980 a 1996, Nueva York recibió alrededor de un millón y medio de inmigrantes, el aporte más significativo del siglo en un periodo de 15 años. A mediados de la década de los noventa, la mitad de los habitantes de la ciudad eran inmigrantes nacidos en el extranjero o hijos de inmigrantes y significaban un tercio de la población joven y estudiantil del sistema público de educación de la ciudad (Rivera-Bátiz, 2003).

A más de 20 años de la tendencia que reconfiguró el flujo migratorio hacia Nueva York, se pueden trazar algunas líneas que esbozan esta nueva historia cotidiana de los latinoamericanos en Norteamérica. En el presente artículo se exploran algunos elementos de los que se valen los migrantes latinoamericanos para reconstruir/deconstruir sus identidades en el contexto de una sociedad huésped urbana y anglosajona. A través del análisis de las dimensiones de inserción e incorporación objetiva y subjetiva, y con el apoyo de entrevistas realizadas en la ciudad de Nueva York, se trata de dejar registro sobre lo concreto y lo interpretativo de la experiencia narrada por los sujetos de la migración internacional.

Los siguientes apartados presentan, en primer lugar, el contexto histórico en el que se generan las nuevas migraciones latinoamericanas hacia Nueva York; después se reflexiona, a través de una serie de imágenes o spots teórico-narrativos, sobre lo objetivo y subjetivo de la inserción y las identidades de los migrantes latinoamericanos en una sociedad huésped. Los fragmentos de entrevistas que se presentan en este artículo fueron obtenidos por el autor mediante trabajo de campo durante el otoño de 2008 y el invierno de 2009, fechas en las que se realizaron alrededor de 65 entrevistas a jóvenes, adultos jóvenes, adultos y líderes migrantes residentes - documentados e indocumentados - de origen mexicano y dominicano en la ciudad de Nueva York.

\section{De Lousaida, Quisqueya y Guadalupe ${ }^{1}$}

Lousaida

Con la antesala ataviada por oleadas de alemanes, irlandeses, judíos, rusos e italianos, a mediados del siglo XX, después de la Segunda Guerra Mundial aparece en la historia americana el primer gran contingente de latinoamericanos en Nueva York: los puertorriqueños.

Entre 1945 y 1959, el flujo migratorio de Puerto Rico hacia Estados Unidos llevó a más de quinientos mil puertorriqueños hacia diversas ciudades norteamericanas. A finales de la década de los años sesenta habitaban más de un millón y en el año 2003 eran casi cuatro millones los boricuas que residían en algún estado de la Unión Americana (Paralitici, 2006).

Durante esos años, cuenta la literatura de viajes y otros relatos de la literatura puertorriqueña ${ }^{2}$ que en el Lower East Side o en Chelsea era común que, al caminar, el andante percibiera el aroma de las fábricas de tabaco de la zona. Dicen que era inevitable observar el ajetreo encantador dentro de las bodegas, los restaurantes, las barberías y las botánicas, espacios que servían como arenas para la socialización y el desenfado.

Sin embargo, no sólo el Lower East Side o Lousaida fueron terrenos de asentamiento para esta comunidad 
de latinoamericanos. Otra área de la ciudad de Nueva York que sufrió o gozó de la ocupación de comunidades latinas o puertorriqueñas fue la del este de Harlem, conocida como El Barrio o el Spanish Harlem: enclave de salsa, son y plena, espacio urbano que hace frontera con el Manhattan blanco al sur y hacia el oeste con el Harlem afroamericano, ahí donde la calle que se nombra por los boricuas Tito Puente se resignifica bajo el título de Malcolm X.

En el año 2000 los puertorriqueños eran el grupo hispano con mayor peso poblacional en la ciudad de Nueva York con alrededor de un millón de habitantes. Empero, este número muestra una tendencia a la baja ya que, desde 1960, la irrupción de los nacionales de República Dominicana y la posterior llegada de los mexicanos en la década de los ochenta vinieron a reconfigurar la escena urbana neoyorquina al punto de que hoy la comunidad puertorriqueña se ha visto obligada a compartir sus espacios urbanos con la creciente población de origen dominicano y mexicano. Un ejemplo lo constituye la ocupación residencial y comercial de la Calle 116 en el enclave cultural nombrado El Barrio (Suárez-Orozco et al., 2002).

\section{Quisqueya}

Por otro lado, entre 1960 y 1990, después de la muerte del dictador Rafael Leónidas Trujillo (1930-1961) —que mantuviera una política de emigración totalmente restrictiva - la República Dominicana se convirtió en la segunda nación latinoamericana que más emigrantes envió a Nueva York. A partir de la década de los setenta la corriente migratoria de dominicanos hacia Nueva York creció constantemente. En promedio, fueron admitidos y documentados por década: 16000 (años setenta), 30000 (años ochenta), 40000 (años noventa), y así permanentemente. La mayoría de estos recién llegados eran inmigrantes jóvenes, 37\% menores de 18 años. De acuerdo con Ramona Hernández y otros estudiosos de la migración dominicana, su llegada se debía - principalmente - a procesos de reunificación familiar (New York City, Department of Planning, 1996, en Smith et al., 2001; Nyberg, 1998; Hernández, 2002).

Sin embargo, más allá de la génesis de la migración dominicana o de buscar en la combinación de factores el impulso que llevó a la República Dominicana a convertirse en una nación de migrantes internacionales, políticos o económicos, los hechos se sintetizan en un intenso y permanente movimiento poblacional que va de Santo Domingo al Pequeño Santo Domingo en el Alto Manhattan: Washington o Quisqueya Heights.

En aproximadamente 45 años, los dominicanos, instalados en un movimiento migratorio que lleva de la República Dominicana a Nueva York —en búsqueda de logros económicos, personales y paz social一, se adaptaron social y culturalmente, y han establecido una articulación económica que, a través de las remesas -económicas, materiales y simbólicas-, ancla a las comunidades a ambos espacios, fortalece las relaciones personales y vincula proyectos de vida construyendo "binational lives" (Guarnizo, 1998).

La concentración geográfica en las distintas áreas de Nueva York y, paralelamente, la consolidación de su espacio transnacional, han logrado posicionar a la comunidad dominicana de Nueva York dentro de la geografía local e inciden política, económica, cultural y socialmente en las vidas no sólo de sus connacionales dentro del territorio estadounidense, sino también fuera de él y, más aún, en las vidas de otros latinoamericanos que comparten los espacios de la ciudad: desde el vecindario, pasando por el sitio de trabajo y los espacios de esparcimiento.

En el mapa neoyorquino, un par de coordenadas hace visible y palpable esta realidad. El área de Washington -Quisqueya - Heights en el Alto Manhattan se presenta a sí misma como el Pequeño Santo Domingo: espacio de referencia para el dominicano recién llegado, la capital simbólica donde igual se vende plátano frito, tostones y cerveza Presidente, así como se escucha bachata y hip hop en un almacén que vende outfit Puma 
y Timberland; todo esto mientras se forman los cuadros de una sociedad civil - real o imaginariamentetransnacional: "La cabeza está aquí, pero el corazón está allá” (estudiante en Dore, Itzigsohn, Hernández; Vásquez, 1998). "Es que, primo, Nueva York no es lo que la gente piensa. Aquí no se pue’ vivir.”3

\section{Guadalupe}

El tercer contingente masivo de migrantes latinoamericanos a Nueva York es el compuesto por los mexicanos a finales de la década de los ochenta. Narra Rudy, un migrante retornado oriundo de la región de la mixteca poblana: "A mis ocho años nos fuimos a Nueva York, mi madre nos dejó y entonces mi padre nos agarró a mí y a mis hermanos... y nos fuimos." Mientras habla, señala un mural donde se observa una virgen de Guadalupe en primer plano sobre una escenografía de edificios encendidos en la noche de la ciudad de Nueva York; añade:

\section{Ese mural lo pinté una vez que regresé, ahí miras cómo me sentía, todo gris y como atrapado ahí... pinté a la virgen de Guadalupe no porque sea muy devoto, pero para que me perdone y más que nada cuide a mis hermanos y amigos que están en prisión por una pelea que tuvimos con unos morenos puertorriqueños en El Barrio (entrevista a Rudy, Tulcingo, 2007).}

Los mexicanos han migrado a Norteamérica - California y Texas- desde mediados del siglo XIX, consolidando a lo largo de los años una red de migración que se reproduce en algunas regiones del país — por ejemplo, la llamada región tradicional de migración - casi de manera natural. Sin embargo, a principios de los años noventa y hasta el día de hoy se han generado nuevas tendencias migratorias que van del centro de la república mexicana hacia la Costa Este de Estados Unidos, concentrándose en la región neoyorquina como destino principal. Se trata de un fuerte contingente que se presenta como diferente y novedoso, no sólo frente a sus connacionales en cuanto a los destinos y circuitos históricos o tradicionales migratorios, sino también frente a los latinoamericanos que históricamente se habían asentado en la región: puertorriqueños y dominicanos. De acuerdo con los datos del Departamento de Salud de la Ciudad de Nueva York, entre 1988 y 1996 se registró un incremento de 232\% de nacimientos entre mujeres mexicanas, tendencia que, de acuerdo con expertos en análisis demográfico, hará de la población mexicana la mayor minoría latina en la Costa Este (Smith, 2006).

Actualmente la población mexicana se ubica como el tercer grupo más grande de inmigrantes después de los puertorriqueños y dominicanos en Nueva York. El $60 \%$ de estos últimos se encuentra dentro del grupo de edad entre 15 y 24 años y, a diferencia de los mexicanos en California o Texas, se desempeña en áreas laborales cien por ciento urbanas como: empacado y venta de alimentos, restaurantes - lavaplatos, busboys, meseros, encargados del aseo o deliveris - , vendedores de flores, empleados de tiendas de abarrotes o mini markets, delis, tintorerías, lavanderías, carwashes o el sector de la construcción.

De acuerdo con el trabajo de Smith (2006), para el caso de los mexicanos no se puede hablar sólo de una concentración geográfica al interior de la ciudad de Nueva York que pueda llevar a un paralelismo analítico frente a los casos del este de Los Ángeles o del distrito de Pilsen en Chicago, donde sí se ve claramente una concentración urbana y simbólica. En Nueva York, más bien, se está frente a una dispersión urbana de la población mexicana que ocupa más de un espacio de concentración étnica. Se localizan tanto en Manhattan como en Brooklyn, el Bronx o Queens y, en todos estos casos, su uso de los espacios geográficos, sociales, simbólicos y políticos configura los ejes de dinámica interétnica: "Hoy, los mexicanos están por todos lados", "El Barrio, menos bacalao y más chile", ambos son encabezados de noticias locales que ilustran la potencial presencia y crecimiento 
de la población mexicana en Nueva York. Desde la década pasada se comenzaron a formar y consolidar vibrantes y pequeñas comunidades de mexicanos en Corona, Sunset Park, Jackson Heights y El Barrio (Dávila, 2004).

En síntesis, las tres presencias latinoamericanas descritas en los párrafos anteriores sirven como referentes directos para configurar en el contexto actual el concepto de "lo hispano o lo latino" en la ciudad de Nueva York. Sin embargo, sobre las dos primeras presencias - puertorriqueña y dominicanase formaron en el imaginario anglosajón las primeras concepciones del "ser latino o hispano", es decir, gente hablando español, comiendo plátano frito, bailando salsa, merengue y bachata; un mambo urbano en una ciudad multicultural lejos de la imagen del "latino" con sombrero de alacrán, las botas de víbora de cascabel, hebillas anchas y plateadas, o los bigotes espesos, porque eso no era el significado de lo "latinopuertorriqueño-dominicano" que habitaba la urbe neoyorquina. Ése era quizá el hispano de la Costa Oeste, el migrante mexicano del sur de Norteamérica, aquel que busca la reconquista de Aztlán en California y trae tatuada una Guadalupe en la espalda mojada.

\section{Lo concreto de lo vivido}

Los procesos y las dinámicas que emanan o se reproducen a raíz de las migraciones son un laboratorio de las relaciones sociales contemporáneas. Toda interacción deviene de movilidades físicas, simbólicas, cognitivas, abstractas y simuladas, las cuales conforman un todo social.

Camaya: Mi jefa vive en Queens. Yo y mis carnales vivimos en Brooklyn, desde que llegué a Nueva York llegué acá a Brooklyn... El primer, primer día que llegué, fui con mi carnal a la (calle) Quinta y nos pusimos a buscar ropa, desde ahí me di cuenta que este país no es para nosotros, pura ropa grandotota, ni la talla más chica me queda (entrevista a Camaya, Brooklyn, 2008). ${ }^{4}$

Hoy en día, a principios del siglo XXI, existen ciudades globales en las que cohabitan microespacios o microsociedades que se distinguen por su concentración étnica: se observa la existencia de una India que habita paralelamente un París, o una Italia rodeada de una China, ambas enclavadas en una ciudad norteamericana. Aunque hace un par de siglos este escenario era inimaginable y ficticio, actualmente es real, múltiple y cotidiano. Pero, ihasta dónde, en la reflexión, esto denota verdaderas transiciones culturales o se trata simplemente de una nueva cartografía enunciada a partir de procesos de anclaje y desanclaje territorial? En otras palabras, ¿cómo se da el diálogo cultural? Camaya reflexiona desde su llegada a la ciudad de Nueva York sobre la distancia social y cultural que presenta la oferta del mercado, en este caso, el mercado del vestido. Para él, su talla es lo que le dicta y denota, en principio, un elemento de choque, un no pertenecer a ese diseño de sociedad.

\section{Periféricos, migrantes y urbanos}

Inside-outside, dentro-fuera: periférico. La ciudad envuelve una dinámica donde lo externo a ella crea vitalidad y la hace dependiente de la movilidad, de los flujos, de las interacciones humanas y de las creaciones culturales. De acuerdo con Park (1999), esta movilidad y estos flujos hacia el interior retroalimentan las ciudades; sin embargo, también las pervierten, y en esa perversión se encuentran los conceptos que refuerzan su idea evolucionista de supervivencia, equilibrio, competencia, dominio y sucesión, elementos que, ya sea en conjunto o actuando por separado, harán que sólo los más aptos sobrevivan a la ciudad o se recluyan para siempre en su área natural ${ }^{5}$ (Bettin, 1982: 70): guetos o zonas residenciales francamente diferenciadas y segmentadas. 
Viví en tres áreas que han sido gentrificadas; viví en la (calle) 84 y Ámsterdam, ahí el abuelo mío y el tío mío, fueron dueños de negocio. En la misma Ámsterdam, ahora tú ves eso ahí y tú nunca hubieras pensado que los dominicanos eran dueños o propietarios de negocios ahí, porque eso ahora es biblioteca Barnes and Noble or Dunking Donuts, cosas más americanas; pero fue el área del Upper West Side donde en los principios del (año) 72 al 76 se hizo la primera comunidad de dominicanos; mucha gente cree que fue Washington Heights, y no es cierto, lo que pasa es que nos han ido recorriendo, la comunidad dominicana cuando llegó aquí en los sesenta vivían de la calle 72 hasta la 96 o 110; mi abuela primero vivió en el Bronx después se mudó para la 83 y Ámsterdam, y duró ahí como hasta el año ochenta, después se movió pa' Queens; porque los dominicanos comenzaron aquí en lo que se llama Upper West Side, la 135, y en Washington Heights, pero hubo un grupo que se fue pa' Queens, lo que es el área de Flushing ahora está lleno de dominicanos; las familias más jóvenes viven ahora muchas en Brooklyn (entrevista a Báez, Manhattan, 2008). ${ }^{6}$

Las ciudades con concentración de migrantes se han caracterizado por poseer una estructura basada en la segregación socio-espacial. Por ejemplo, en toda gran urbe estadounidense con presencia inmigrante se puede encontrar el barrio chino, la pequeña Italia, el barrio latino, el enclave mexicano, la calle de los coreanos, el barrio de los afroamericanos y otros que se van sumando a la heterogeneidad étnica y a la gentrificación acumulada. La distinción se define en la pigmentación de la piel, el idioma, la madurez de la migración del grupo, los recursos económicos, el capital cultural y la mayor o menor discriminación social y laboral. Se dice que un barrio además de ser una expresión geográfica es una localidad con sentimientos, tradiciones e historia propia (Lezama, 2010).
Los inmigrantes, como agentes intersticiales, abandonan un espacio de poca movilidad para insertarse en un colectivo de heterogeneidades distantes e individualizadas donde la competencia metropolitana es fáctica y real. El barrio migrante, el underground, el gueto, la calle, la esquina o la pandilla, todas son encarnaciones en y del territorio.

\section{Inserción estacional o permanente}

La migración, como movimiento estacional, circular y en cortos periodos semejante a la estrategia de las aves de paso, como metáfora de lo periódico y rítmico, con el tiempo se ha modificado dando paso a otras estrategias migratorias de temporalidades más duraderas, algunas tan prolongadas como la propia vida (Pioré, 1979).

En el mapa global de movilidades, las migraciones contemporáneas, los colectivos y comunidades de migrantes, llámense cubanos, mexicanos, judíos, asiáticos o italianos, han sido estudiados predominantemente desde el paradigma de la asimilación. Sus resultados, pensados bajo el esquema de éxito o fracaso, han variado indistintamente en cada uno de los casos, ya que los grupos étnicos no son entes homogéneos. Aunque el enclave o el cluster cultural cohesione a una mayoría de una minoría migrante, al interior se reproducen relaciones más densas, las cuales superan la mera identificación que significa el origen nacional; por ejemplo, la identificación de pares, etaria, de género y de clase. Estas relaciones deben analizarse con parámetros y marcos conceptuales diferentes a los que están interiorizados en las teorías norteamericanas que explican la incorporación de los inmigrantes.

Pensar la inserción y la incorporación del migrante en lo local, los tipos de vínculos y relaciones sociales que produce en el lugar de destino, así como su éxito o fracaso en los mercados laborales o los espacios escolares, depende, de acuerdo con las teorías ortodoxas de la asimilación (Alba y Nee, 2003), del exacto engranaje de una serie de variables individuales y colectivas, 
internas y externas al migrante como el capital humano, las redes sociales, el tipo de mercado - segmentado o no-, la capacidad de adaptación, el capital social, la solidaridad al interior del grupo étnico, el contexto y las condiciones de salida, el contexto y las condiciones de recepción, etcétera.

Rafael: Desde el principio, en los primeros días (de su llegada a Nueva York) pasaron cosas muy fuertes y tuve que ayudar, la escuela (donde trabajaba su esposa) estaba en mantenimiento y tuve que subir las escaleras de esas altas y yo limpiando las ventanas de esos edificios. Siempre estuve dispuesto a irme a limpiar departamentos, yo vine a este país a hacer lo necesario para alcanzar mis sueños....siento como este país te ofrece educación y seguridad pero también como que se vive un mundo ficticio, y como que no se vive la realidad, no te sé decir, mira no sé, no te puedo decir exactamente (entrevista a Rafael, Harlem, 2009)?

De acuerdo con Foner (2001), desde 1965 a la fecha la incorporación de los nuevos inmigrantes a las sociedades huéspedes o de arribo -migración surnorte, o la llamada también de migración de países periféricos a países centrales-, no se ha caracterizado por una asimilación, incorporación o americanización completa en términos formales u ortodoxos. Además, en el contexto actual la tecnología y las redes densas han resignificado aún más el modo de incorporación de grupos minoritarios en sociedades multiétnicas; la dispersión o la lejanía geográfica no necesariamente significan el aislamiento o pérdida de contacto con el lugar de origen; y la identificación con el lugar de destino, en lo individual y estructural, no se realiza sólo sobre una imagen o ideal de la sociedad huésped, es decir, el ser y hacerse americano no constituye para los nuevos migrantes incorporarse a la sociedad de los White Anglo Saxon Protestan (WASP), en tanto orden social dominante, ya que en la diversidad étnica y sociocultural han encontrado muchos significados y vías de incorporación alejadas del mainstream.

En este sentido, el retrato de Rafael permite observar un proceso de incorporación segmentada como inmigrante, el cual, si decide permanecer en la sociedad de destino, está obligado a adscribirse temporal o permanentemente en una dinámica que, a partir de cero y con limitados recursos, tendrá que reconstruir su trayectoria laboral. En otras palabras, una vez conocido este umbral, los sujetos migrantes adquieren conciencia de sus limitadas oportunidades y de las restricciones para sus expectativas de vida. De ahí se genera una primera tensión entre el migrante y los nativos también derivada de la distribución y acceso a recursos bajo condiciones inequitativas y antidemocráticas, lo que al final desemboca en segregación, discriminación económica y racial, e impedimentos para alcanzar las metas de movilidad ascendente (Portes, 1996a; 1998; 2001).

En otras palabras, toca reflexionar en torno a la vida de los migrantes y sus generaciones: ¿bajo qué parámetros o posturas se medirán las estrategias de asimilación de los sujetos en un marco de movilidades globales?, pero también icuál es la percepción del individuo como sujeto migrante sobre su inserción, es decir, al explorar en su subjetividad?

\section{Inmigrantes o sociedades inciviles}

En la vida y práctica cotidianas del migrante internacional, el ejercicio de derechos traspasa el mero ámbito de lo político y lo cívico —entendidos en su acepción formal-, dando paso a formas o construcciones de lo ciudadano desde el ámbito de lo cultural como forma de ejercer una ciudadanía vivida o también marginal (Isin, 1997).

Por ejemplo, en el año 1993 los clubes de migrantes mexicanos de California se unieron en contra de la Proposición 187 firmada en el año 1994, la cual principalmente proponía restringir el acceso a los servicios públicos - educación y salud-a los 
inmigrantes indocumentados. En una carta dirigida al gobernador Pete Wilson, publicada en el diario $\mathrm{La}$ Opinión de Los Ángeles, la sociedad civil migrante ${ }^{8}$ se hizo presente como unidad política al manifestar su descontento. Textualmente refiere:

Ante la presente campaña que pretende generar odio contra los inmigrantes latinos, los firmantes repudiamos la política del gobernador Pete Wilson que en su afán de hacer del inmigrante indocumentado el chivo expiatorio de la presente crisis económica, ha distorsionado y alterado los hechos sobre los indocumentados (Escala, 2005: 98).

Además de expresar el malestar de la comunidad inmigrante frente a actitudes racistas y el trauma nacionalista, la carta se configura como un estandarte contra la indefensión. Más allá del resultado final, esto contribuyó a que el colectivo se posicionara como sujetos políticos y de derecho aun en condiciones de indocumentación migratoria.

En la sociedad política estadounidense se ha puesto reiteradamente sobre la mesa de discusión el asunto de la lealtad en el proceso de inserción e incorporación de los migrantes e inmigrantes con o sin participación política transnacional; el argumento que sostiene su discusión es que estos últimos -inmigrantes con calidad de ciudadanos - no deberían participar en la política de otros países - así se trate de su sociedad de origen - ya que podría llevarles a perder la ciudadanía estadounidense obtenida. Lo anterior bajo el supuesto de que dicha participación pone en duda el juramento de guardar lealtad y fidelidad a su nueva sociedad. En este sentido, la ciudadanía, en su acepción tradicional, parece que reclama exclusividad y competencia de quien la adquiere, cerrando el camino a la ciudadanía transnacional —dos o más lealtades-. Ante ello, y ante la imposibilidad o la esquizofrenia de vivir como migrante en la dualidad de la inclusión y la exclusión, de permanecer en medio de la polaridad racial y, sobre todo, ante la incertidumbre que genera vivir bajo un estatus legal ambiguo, vulnerable y no autorizado, la pregunta obligada es: ¿cómo conciliar dos o más ciudadanías depositadas en un mismo individuo sin que necesariamente una de ellas perviva y se configure necesariamente como ciudadanía marginal?

En Estados Unidos se ha dicho que ser migrante y latino es una condición doblemente contracultural: ni blanco ni protestante; sino, en contraste: moreno y católico. Los migrantes adultos y jóvenes - hijos ilegítimos de la nación — han adquirido particularidad en el espacio social, político y cultural norteamericano porque han recreado a lo largo de la historia su espacio al margen de la institucionalidad que dictan las formas blancas o el mainstream de la organización social. Emprenden, basados en sus propios vínculos y recursos, redes de solidaridad endógenas y periféricas donde el barrio, el gueto y el vecindario se presentan como escenarios en los que su etnicidad se configura también en forma de cuestionamiento y resistencia; configuran una identidad política de sangre, un ser y hacerse ciudadanos sobre un espacio simbólicamente apropiado donde defender el derecho va más allá de imaginar una muerte; es real que les significa vivir, volverse presente y presencia, ciudadanos marginales, sociedades inciviles.

\section{Migrar, trastocar, mutar}

La virgen no es la virgen. La bachata es otra bachata. América no es América. Bajo la existencia de sentimientos comunes se configuran los sentidos y el significado de todas las cosas. La presencia de los migrantes latinoamericanos en Norteamérica obliga no sólo a pensar a esa nación de forma distinta, sino a enunciarla con otros nombres y en otros idiomas. Los lugares y las ciudades norteamericanas han sido resignificadas por los migrantes que las habitan. Así, el East Harlem se convierte en El Barrio, el Upper Manhattan en Quisqueya Heights, y Nueva York 
en Guadalupe. En el migrar-habitar, la metáfora de la presencia -individual y colectiva- se contiene, representa y multiplica.

Migrar trastoca y muta la subjetividad: el sentir y el sentido social. Cada pregunta, cada porqué en el camino del migrante, forma parte de una nota extensa al pie de página de su vida social, de sus actitudes, percepciones, sentimientos, emociones y acciones, todas representadas relacional, individual o colectivamente (Chambers, 1994).

\begin{abstract}
El Marley: cuando llegué, me la pasaba con mi carnal, él tenía su bicicleta y aparte un primo también, y yo le pedía la de él, y ya nos íbamos los dos en bicicleta, íbamos a panbolear, a echar el fucho (jugar futbol); y así fue la primera semana, nada más dando el rol, fue ahí cuando conocí a más valedores, de ahí me conectaron para una bakery... ya como a las tres semanas ya me fui, supuestamente que a trabajar, como dirían acá a "barrer dólares" ino?, era en las mañanas un barredor de dólares...ya después conocí a los de la (calle) 47, nos decían los rockeros de la 47, entonces, era uno (trabajador) y otro en la noche (entrevista a El Marley, Manhattan, 2009). ${ }^{9}$
\end{abstract}

¿Es posible diseñar o simular sujetos ad hoc en tiempos y espacios sociales móviles? El Marley, como sujeto incorporado a una dinámica de choque de roles e identidades, juega intermitentemente con su posición de sujeto móvil. En este sentido, Néstor García Canclini (2001), situado sobre la ola del pensamiento posmoderno y emulando las ideas de Paul Ricoeur, que concibe al sujeto no a partir del sujeto mismo, sino como un proceso de construcción cotidiana e interactiva, duradera o efímera, coloca en medio de una encrucijada la existencia y la certeza de los supuestos de la subjetividad cartesiana del racionalismo moderno que identificaban al sujeto como sujeto de conocimiento. Es decir, se vincula al sujeto a eso que da realidad y sentido a la existencia humana y que además es capaz de autorreflexionar; de ahí el significado del axioma "pienso, luego existo"10 que postula un "yo autónomo" alrededor de un mundo constituido por la propia capacidad de pensar y razonar del sujeto, y desprendido en su razón totalizadora de las pasiones, los sentimientos, las fobias o los afectos (MartínBarbero, 2003; García, 2001; Castrillo, 2011; Descartes, 1977).

En otras palabras, en el mundo social contemporáneo se presenta un sujeto que se diseña en un contexto relacional, donde el self individual se recrea en la convivencia con los otros, sean individuos, instituciones o colectivos, en un proceso identificatorio que internaliza al que mira y es mirado, siendo sujeto para sí y para otros, en un proceso que contempla la lectura del otro que observa.

En la concepción clásica de identificación, al sujeto se le definía nacional, local y lingüísticamente sobre la base de "estructuras de sentimientos de larga duración" (García, 2001: 115). Ahora estas estructuras se desbordan debido a que, bajo la lógica del intercambio global, no sólo las economías se transnacionalizaron, sino que también la cultura intercambia sus códigos en una dinámica cuasi corporativa. Las industrias culturales viajan de norte a sur y viceversa, produciendo en el cruce cultural andamiajes y repertorios simbólicos y materiales de los que se valen los sujetos al momento de insertarse en una nueva sociedad y al diseñar sus paisajes, sus identidades y sus estructuras de reconocimiento cultural, laboral y político (García, 2009; Harvey, 2009; Augé, 2000).

¿Mito, imaginación o realidad? Al hablar de la inserción y la identidad del migrante, una alternativa es observar éstas desde relaciones multinivel y multirreferenciales, ya que se trata de códigos específicos instalados en el stock de pertenencias puntuales y graduales o, dicho de otro modo, el individuo migrante aborda y materializa su subjetividad vía representaciones sociales, lingüísticas, simbólicas y estéticas por las cuales las dimensiones de realidad 
e imaginación se yuxtaponen en espacios culturales específicos.

Deslocalizados o globalizados, apocalípticos o integrados, todos, en tanto sujetos capaces de realizar una lectura sobre sí mismos, interiorizan también la lectura del otro que observa, cuestiona, reconfigura o reafirma sus ideas de nación, sociedad, identidad y pertenencias más allá del territorio natural de adscripción.

\section{Itinerarios del sujeto migrante}

La primera experiencia que define al individuo como sujeto migrante es al partir, al dejar el hogar y comenzar el camino hacia ese otro espacio conocido por su nombre, pero desconocido en todas sus partes. Por eso ahí, en medio de esa experiencia, de ese primer "hacer migración" como práctica, ya sea en el desierto, la carretera, el mar, la balsa, la yola ${ }^{11}$ o la camioneta, se recupera y se encarna el primer contacto con esa otra condición que les denomina sujetos migrantes. Desde ese punto y en adelante, en el itinerario diario, al habitar el "no lugar" de la migración, se verán enfrentados cotidianamente con nuevos espacios, nuevos lenguajes, nuevos símbolos, nuevas deidades y nuevos yos para adaptar e interpretar su inserción, sus prácticas y sus espacios de reconocimiento. En el trabajo, la escuela, la calle, la plaza pública, el comercio, la política, la iglesia, en el cruce constante de sintagmas y de símbolos, el sujeto significa, construye y reconstruye sus formas de ser igual y diferente.

Dayana: llegué hace cinco años y para mí fue bien difícil adaptarme a una nueva cultura, aprender el idioma fue un gran desafío para mí y gracias a Dios que pude aprender el idioma, porque muchas personas no me trataban bien, me discriminaban por no hablar inglés... fue increíble para mí, ahora en mi primer año en la universidad saqué una nota excelente y sólo tengo cinco años aprendiendo, me fue muy bien y sigo adelante, soy más dominicana que nunca, pero ahora también soy de aquí de Harlem (entrevista a Dayana, Harlem, 2009). ${ }^{12}$

Los espacios de la incorporación y la vida diaria dejan de ser sólo un lugar de hábito y destino para convertirse en estructuras inconclusas, indefinibles y antiestáticas: sin obviedad ni simulación. Permutando e intercambiando los usos urbanos en una dinámica de sustitución clandestina, los espacios habitados por migrantes se van trasformando y son tomados paulatinamente. En Casa tomada (2007), Julio Cortázar narra la historia de Irene y su hermano, quienes terminan por ser desalojados poco a poco de cada una de las habitaciones de la casa. La anécdota puede leerse de diversas formas, una de ellas como metáfora de lo que ocurre en las sociedades receptoras de migrantes: la casa es el espacio urbano de la nación, y los personajes, Irene y su hermano, encarnan a los "nativos", que en la narración terminan por ser desalojados por los "no nativos" o los inmigrados. Más allá de la ficción o la realidad, de las fuerzas de penetración de uno u otro sujeto social, ya sea el nativo o el inmigrado, la interpretación lleva al enunciado siguiente: "el espacio es experiencia práctica, se produce en la interacción e intersubjetividad" (Dávila, 2004; Lindón, 2001: 11).

El relato de Dayana parte de un horizonte en el que, por un lado, existe una dificultad subjetiva para la adaptación como migrante y, por otro, se enfrenta objetivamente a una discriminación social resultado de falta de conocimiento del idioma inglés. Su narrativa como itinerario señala en principio el obstáculo y culmina con una meta cumplida. Si bien esto no es indicativo de un patrón generalizable, habla de una construcción objetiva-subjetiva de la movilidad y la incorporación.

La imaginación, el lenguaje y los signos enunciados en y por el sujeto, en y por la ciudad, al final constituyen la matriz que se llama cotidianidad-espacio-sujeto y que, dicho de paso, es más coincidente con una 
imagen de heterogeneidad sin restricciones que con una imagen dicotómica. Es decir, una vez insertos en la sociedad, icómo se representan frente a frente, face to face, migrante y migrante: asiático y africano; latinoamericano y europeo; mexicano y dominicano; salvadoreño y colombiano; blanco y negro?

\section{De la identidad y la movilidad}

La identidad es una espiral grabada en la yema de los dedos. Esto en parte es cierto y en parte no. Es cierto en el sentido genético: cada individuo es único y auténtico. Es falso en el sentido social ya que, si bien cada cabeza es un mundo, existen patrones y actitudes que se repiten, se suceden uno al otro y se recrean en la interacción entre individuos y entre los distintos espacios sociales. La identidad como complejidad, individual o colectiva, visible o invisible, va tatuada a flor de piel.

En la literatura sociológica se habla de identidades e identificaciones como representaciones o dispositivos de reconocimiento estructurados por empatías y rasgos compartidos, anclados a elementos políticos, religiosos, económicos, sociales y culturales, sean colectivos o individuales, móviles o inmóviles. Las identidades contemporáneas, más allá de cualquier noción esencialista, son constructos sociales transversales a las condiciones materiales e históricas del todo social. De esta forma los sujetos construyen sus discursos y sus prácticas en relación a las distinciones de género, edad, ideología, logro educativo, hábitos de consumo, ubicación espacio-temporal, experiencias de movilidad y expectativas. De ahí la importancia de generar un discurso de la distinción (Hall y Du Gau, 2003; García, 2009: 30).

Victoria: De chiquitita a mí me gustaba, yo tenía orgullo de decir que yo podía hablar en más de dos lenguas vea, pero a veces no me gustaba porque yo quería hablar en español y no me dejaban, los maestros no lo entendían, o yo quería decir algo en inglés y mi mamá no me entendía, y mi papá tampoco... Cuando tenía como 15, 16 años empecé a notar que habían más mexicanos en la escuela aparte de los que conocía, porque en mi salón no había mucho hispano, había poquito: puertorriqueños y dominicanos que otra vea, cuando ya estuve en la prepa empecé a preguntar: iy tú de dónde eres? y me decían: yo soy colombiano; iy tú de dónde eres? yo soy italiano y filipino, y coreano y no sé qué..., yo digo definitivamente que soy americana pero no mexicana, porque no siento que soy, bueno, ni de aquí ni de allá, para hacerlo más fácil, en palabras más simples (entrevista a Victoria, Bronx, 2009).13

Las pertenencias y las apropiaciones objetivas y subjetivas pasan entonces por la historia, la ideología, la clase social, la generación, el territorio y la biografía personal, generando una suerte de subcultura latente donde, a través de las décadas y en el puente de un siglo a otro, las constantes parecen ser las mismas: desacuerdo, incertidumbre, rechazo a la cultura parental, búsqueda de espacios personales, etcétera. La identificación dinámica, de la mano del cambio tecnológico y cultural, constituye plataformas para la expresión que se sitúan más allá de la contra y la subcultura en procesos deconstructivos y posmodernos: ida y vuelta hacia la legitimidad (Valenzuela, 2009; Narváez, 2007).

\section{Lo transnacional como anécdota}

En las dos décadas de vida del concepto de lo transnacional migrante en medios académicos y no académicos, éste ha sido vinculado a lo político, a lo religioso y a lo económico, y también como práctica concreta cuyo objetivo es mantener la presencia y permanencia migrantes en sus comunidades de origen y destino. Sin embargo, poco se sabe del sentido de traslape, de negociación y de parcialidad que contiene, sentidos que persisten en las relaciones que desarrollan los migrantes contemporáneos. 
Esa mañana despierta en su rancho de Zacatecas, por la tarde-noche cena pupusas salvadoreñas en un local del South Central de Los Ángeles, al llegar a casa intercambia algunas palabras en spanglish con su hija mayor que se encuentra de visita en la casa familiar mientras pasa el periodo vacacional: ella estudia en la Universidad de California en Santa Cruz y planea hacer un posgrado en literatura hispana en la Universidad Nacional Autónoma de México, entretanto, en la cocina su mujer prepara burritos para los hijos menores que saldrán muy temprano para pasar el verano en casa de los abuelos en Celaya, Guanajuato (Narváez, 2012: 121).

Más allá de la anécdota, el retrato trata de hilar y perfilar las dimensiones por las que atraviesa el acto de habitar como migrante en el fenómeno de lo global, ya que en esa dinámica se halla una semántica multidimensional donde migrar y ser migrante decodifica en el campo de las movilidades signos y códigos que rebasan el factor o los factores principales que iniciaron el movimiento.

La diáspora latina vive, examina e inventa, sobre discursos del presente y del pasado, del antes y el después de la sociedad huésped, en una dinámica adaptativa de su self make, de su lenguaje y su cultura, creando un caló para cada geografía multicultural en la que posan su imaginario social, entendido — siguiendo a Cornelius Castoriadis (2002) - como esa "creación incesante y esencialmente indeterminada de formas e imágenes a partir de las cuales solamente puede referirse a algo. En otros términos, lo imaginario no representa en el sentido de, no necesariamente remite a algo real o sustituye una presencia" (Hiernaux, 2006: 14). De ahí la idea de vivir una realidad cotidiana traslapada, autonegociada, parcial y subjetiva.

Los migrantes catalizan su imaginario y lo transnacionalizan; basan en ello una libertad social que les impide caer en el sometimiento que normaliza la relación con los que no pertenecen a su comunidad: con los nativos. Negocian sus pertenencias cotidianamente sobre múltiples escenarios: la comunidad, la nación, el país huésped, el barrio, el enclave, el lugar de trabajo, la escuela y la familia.

Si las condiciones de existencia son buenas o no, los atributos de la imaginación, en principio, les liberan del cuerpo, les brindan movilidad intangible e ilimitada. Lo transnacional es ahora una condición del imaginario social donde, de manera crítica, intenta abarcar conocimiento cierto y empírico, algo invisible, algo intangible, pero sin duda real:

[...] no se puede explicar ni el nacimiento de la sociedad ni las evoluciones de la historia por factores naturales, biológicos u otros, tampoco a través de una actividad racional de un ser racional (el hombre). En la historia, desde el origen, constatamos la emergencia de lo nuevo radical, y si no podemos recurrir a factores trascendentes para dar cuenta de eso, tenemos que postular necesariamente un poder de creación, una vis formandi, inmanente tanto a las colectividades humanas como a los seres humanos singulares. Por lo tanto, resulta absolutamente natural llamar a esta facultad de innovación radical, de creación y de formación, imaginario e imaginación (Castoriadis, 2002: 94).

Fundado en el cuestionamiento de formas convencionales de comprensión del todo migratorio, el transnacionalismo ha dotado sin duda de marcos interpretativos más amplios e incluyentes que ven al migrante como sujeto y no como objeto de lo global contemporáneo. La intermitente incorporación de esquemas más complejos de movilidades no sólo reta a la academia a asir e incorporar cabalmente estos procesos y prácticas, sino que sobrepasa los dispositivos disponibles para coherentemente responder con un solo horizonte a un fenómeno fugaz y permanente. 


\section{Epílogo}

Los cambios en el perfil y la dinámica de la migración contemporánea incorporan elementos de geografías sociales disímbolas, creando un mapa de prácticas y sentidos en el que no queda siempre muy claro dónde es el ahora y el después; dónde inicia el hecho, el recuerdo o la interpretación de la realidad cotidiana de la diáspora. En cada uno de los apartados se tratan de unir los puntos que han colocado diversas teorías sobre el espacio de los estudios de migración, a modo de generar un ensamble que dote, con lo ya provisto, de alternativas de abordaje para la investigación y la reflexión sobre la migración y los sujetos migrantes.

En una idea compleja de identificaciones migratorias, ser minoría define una posición que marca el paso y la relación de éxito o fracaso con lo nativo, la distancia entre el grupo étnico y la sociedad huésped. Elías Canetti(2005) habla del "temor a ser tocado"; el migrante y el nativo también temen ver transformada su cultura profunda, de ahí la exaltación de signos idiosincráticos colgados en el cuello, plasmados en murales, a la venta en aparadores, estampados en playeras, anunciados en letreros luminosos e interiorizados en la estética personal. Este temor también se expresa en la movilidad del sujeto migrante al interior de las ciudades (Portes y Zhou, 2003; Glick, 1992).

El self del migrante latinoamericano adquiere sentido en los Estados Unidos frente a los otros que, a su vez, se saben afroamericanos, nativos blancos americanos, italianos, rusos o asiáticos, pero iqué ocurre cuando se devela el significado de lo "latino" como concepto? Dentro de él caben mexicanos, dominicanos, salvadoreños, ecuatorianos, colombianos, hondureños o haitianos, gama extensa de multiculturalidad y multirracialidad. Si bien los latinos frente a frente se distinguen unos de otros por el color de la piel, el cabello, la estatura, el acento e incluso el idioma, son una amalgama que el resto de la sociedad expresa sólo en singular y no su multiplicidad (Kasinitz et al., 2008).

\section{Notas}

${ }^{1}$ Lousaida:área de residencia de muchos puertorriqueños y cuna del primer movimiento literario latino en Nueva York, los Nuyorican Poets, donde se ubican Miguel Algarín y Miguel Piñero. Actualmente es hogar de hipsters y bohemios burgueses como resultado del proceso de gentrificación. Quisqueya es el nombre con el que los indígenas tainos identificaban a la República Dominicana en la actualidad y en el contexto migratorio hacia el área de Washington Heights en Manhattan. Se le ha renombrado metafóricamente Quisqueya Heights ya que esa área se ha convertido, debido a su alta concentración de población de origen dominicano, en el corazón simbólico de la diáspora dominicana. Guadalupe es el nombre metafórico que se usa en este artículo para nombrar los nodos geográficos que ocupa la población de origen mexicano en la ciudad de Nueva York.

2 La literatura puertorriqueña-neoyorquina, señalan algunos especialistas, fue pionera dentro de lo que después se concentraría en la literatura de inmigrantes latinoamericanos en Nueva York. Entre los primeros escritores -finales del siglo XIX - se encuentran algunos exiliados como Eugenio María de Hostos, Ramón Emeterio Betances y Lola Rodríguez. Sin embargo, el momento cumbre para la literatura puertorriqueña se da en 1950 y décadas posteriores, cuando bajo la Operation Bootstraps se produjo una migración masiva de trabajadores agrarios — llamados jíbaros - desplazados del campo, desde la isla hacia la ciudad de Nueva York y otras ciudades de Estados Unidos (Marceles, 2000).

${ }^{3}$ Diálogo de Balbuena, personaje del filme Nueva Yol, largometraje dominicano que retrata la vida de los migrantes dominicanos en la Gran Manzana.

${ }^{4}$ Entrevista realizada por el autor en 2008 en el área de la Quinta en Brooklyn, Nueva York. Camaya es un joven mexicano de 19 años que al momento de la entrevista no trabajaba de manera formal ni estudiaba. 
${ }^{5}$ Según Park, la comunidad urbana se ofrece al observador atento como un conjunto de áreas más pequeñas, distintas unas de otras, pero todas más o menos típicas, que están definidas por una característica clave: su función o principio catalizador de la comunidad que allí vive. Toda gran ciudad tiene su centro comercial, sus áreas exclusivamente residenciales, sus áreas industriales, sus ciudades satélites.

${ }^{6}$ Entrevista realizada por el autor en 2008 en el área de Washington Heights en Manhattan, Nueva York. Báez es un joven de origen dominicano de 29 años que al momento de la entrevista trabajaba dirigiendo programas para jóvenes inmigrantes latinos, especialmente dominicanos.

${ }^{7}$ Entrevista realizada por el autor en 2009 en el área de Harlem en Manhattan, Nueva York. Rafael es un joven migrante dominicano, químico de profesión, de 27 años. Al momento de la entrevista trabajaba como voluntario realizando tareas de conserje en una iglesia católica orientada a atender a la población en español.

${ }^{8}$ En el desplegado titulado "Carta abierta al gobernador Pete Wilson", publicado el 23 de septiembre en el diario La Opinión, aparece un listado de los distintos clubes, asociaciones y otros actores sociales, fundamentalmente con el objetivo de "defender los derechos humanos de los inmigrantes indocumentados" (Escala, 2005: 98).

${ }^{9}$ Entrevista realizada por el autor en 2009 en el área de Manhattan, Nueva York. El Marley es un joven mexicano de 23 años que al momento de la entrevista trabajaba por día como artesano.

${ }^{10}$ Posición donde el sujeto se piensa a sí mismo pensando.

${ }^{11}$ Se conoce como yola a la pequeña embarcación - ligera y movida con remos- que usan los migrantes dominicanos para trasladarse de su isla hacia Puerto Rico.

${ }^{12}$ Entrevista realizada por el autor en 2009 en el área de Harlem en Manhattan, Nueva York. Dayana es una joven migrante dominicana, de 20 años, que al momento de la entrevista cursaba el primer año de educación universitaria.
${ }^{13}$ Entrevista realizada por el autor en 2009 en el área del Bronx, Nueva York. Victoria es una joven migrante mexicana, de 23 años, que al momento de la entrevista cursaba la carrera de enfermería en la Universidad de la Ciudad de Nueva York, en el Bronx.

\section{Bibliografía}

Alba, Richard y Victor Nee (2003), Remaking the American Mainstream. Assimilation and Contemporary Immigration, Cambridge, Mass: Harvard University Press.

Augé, Marc (2000), Los no lugares. Espacios del anonimato, España: Gedisa.

Basch, Linda, Nina Glick Schiller y Cristina Szancton Blanc (1994), Nations Unbound: Transnational Projects, Postcolonial Predicaments, and Deterritorialized NationStates, Langhorne, Pa: Gordon and Breach Editor.

Bettin, Gianfranco (1982), Los sociólogos de la ciudad, Barcelona: Gustavo Gili.

Blanco, Cristina (2000), Las migraciones contemporáneas, España: Contempo Alianza.

Bogen, Elizabeth (1987), Immigration in New York, Nueva York: Praeger.

Canetti, Elías (2005), Masa y poder, Barcelona: Debolsillo, Castoriadis, Cornelius (2002), Figuras de lo pensable (Las encrucijadas del laberinto VI), México: Fondo de Cultura Económica.

Castrillo, Dolores (2011), "Del sujeto cartesiano al sujeto del psicoanálisis en Jacques Lacan”, en Revista del Nuevo Centro de Estudios del Psicoanálisis. 〈http://www. nucep.com/referencias/Sujeto.htm> [10 de junio de 2012].

Cerbino, Mauro (2008), Otras naciones, Quito: FLACSO.

Chambers, Iain (1994), Migración, cultura, identidad, España: Amorrortu.

Cortázar, Julio (2007), Casa tomada y otros cuentos, México: Alfaguara.

Dávila, Arlene (2004), Barrio Dreams Puerto Ricans, Latinos, and the Neoliberal City, Berkeley: University of California Press. 
Davis, Mike (2000), Magical urbanism: Latinos reinvent the US city, Londres: Verso.

Descartes, René (1977), Meditaciones metafísicas con objeciones y respuestas, Madrid: Alfaguara

Duany, Jorge (2002), The Puerto Rican Nation on the Move: Identities on the Island and in the United States. Chapel Hill: University of North Carolina.

Escala Rabadán, Luis (2005), "Derechos humanos y asociaciones de migrantes mexicanos en California", en Revista Migraciones Internacionales, México: El Colegio de la Frontera Norte, julio-diciembre, vol. 3, pp. 84-107.

Feixa, Carles (1998), El relojde arena, México: Causa Joven. Flores, Juan (2000), From Bomba to Hip Hop. Puerto Rican Culture and Latino Identity, Nueva York: Columbia University Press.

Foner, Nancy (2001), New immigrants in New York, Nueva York: Columbia University.

García Canclini, Néstor (2001), "Redescubrimiento del sujeto, reconstrucción de la ciudadanía", en Iztapalapa, núm. 50, enero-junio, México: Universidad Autónoma Metropolitana, Iztapalapa. pp. 101-118,

García Canclini, Néstor (2009), Consumidores y ciudadanos. Conflictos multiculturales de la globalización, México: De Bolsillo.

Glick Schiller, Nina, Linda Basch y Cristina BlancSzanton (1992), Towards a Transnational Perspective on Migration: Race, Class, Ethnicity, and Nationalism Reconsidered, Nueva York: New York Academy of Sciences.

Guarnizo, Luis Eduardo (2007), "El vivir transnacional”, en Ariza, Marina y Alejandro Portes (eds), El país transnacional: migración mexicana y cambio social a través de la frontera. México: UNAM-IIS.

Guarnizo, Luis Eduardo (2008), Londres latina, México: Miguel Ángel Porrúa.

Hall, Stuart y Paul Du Gay (comps.) (2003), Cuestiones de identidad cultural, Buenos Aires: Amorrortu.

Harvey, David (1998), La condición de la postmodernidad: investigación sobre los orígenes del cambio cultural, Buenos Aires: Amorrortu.
Harvey, David (2009), Social justice and the city, Atenas: University of Georgia Press.

Hernández, Ramona (2002) The Mobility of Workers under Advanced Capitalism: Dominican Migration to the United States, Nueva York: Columbia Universtiy Press.

Hiernaux, Daniel (2006), “Los centros históricos: iespacios posmodernos? (De choques de imaginarios y otros conflictos)", en Lindón, Alicia, Miguel Ángel Aguilar y Daniel Hiernaux (coords.), Lugares e imaginarios en las metrópolis, Barcelona: Anthropos/Universidad Autónoma Metropolitana-Iztapalapa, pp. 27-42.

Isin, Engin F. (1997), "Who is the new citizen? Toward a genealogy”, en Citizenship Studies, núm. 1, vol. 1, pp. 115-132.

Kasintz, Philip, John Mollenkopf, Mary Waters, y Jennifer Holdaway (2008), Inheriting the City. The Children of Immigrants Come of Age, Cambridge, Massachusetts y Londres: Harvard University Press/ Russell Sage Foundation.

Lezama, José Luis (2010), Teoría social, espacio y ciudad, México: El Colegio de México/Centro de Estudios Demográficos y Desarrollo Urbano.

Lindón, Alicia (2000), La vida cotidiana y su espaciotemporalidad, Barcelona: Anthropos/El Colegio Mexiquense.

Martín-Barbero, Jesús (2003), "Saberes hoy: diseminaciones, competencias y transversalidades", en Revista Iberoamericana de Educación, núm. 32, agosto de 2003.

Narváez Gutiérrez, Juan Carlos (2007), Ruta transnacional: a SanSalvador por Los Ángeles. Espacios de interacción juvenil en un contexto migratorio, México: Miguel Ángel Porrúa/ UAZ/IMJUVE.

Narváez Gutiérrez, Juan Carlos (2009), "El papel de la migración en las pandillas transnacionales. Una visión desde México", ponencia preparada para el Foro 15 años de pandillas en Centroamérica: balance y perspectivas, El Salvador: FLACSO.

Narváez Gutiérrez, Juan Carlos (2012), One Way Trip: inserción, identidad y cultura transnacional, México: 
Centro de Estudios Migratorios del INM/Tilde Editores/Conaculta/Fonca.

Nyberg Sorensen, Ninna (1998), "Narrating Identity Across Dominican Worlds", en M.P. Smith y L.E. Guarnizo (eds.), Transnationalism from Below, New Brunswick, Canadá: Transaction Publishers,

Park, Robert Ezra (1999), La ciudad y otros ensayos de ecología urbana, Barcelona: Ediciones del Sebal.

Park, Robert, R.D. McKenzie y Ernest Burgess (1925), The City: Suggestions for the Study of Human Nature in the Urban Environment, Chicago: University of Chicago Press.

Pioré, Michael (1979), Birds of Passage. Migrant Labor and Industrial Societies, Nueva York: Cambridge University Press.

Portes, Alejandro (1996a), The new second generation, Nueva York: Russell Sage Foundation.

Portes, Alejandro (1996b), "Trasnational Communities: Their Emergence and Significance in the Contemporary World-system", en Korzeniewidcz, R.P. y W.C. Smith (eds.), Latin America in the World Economy, Westport, Conn: Greenwood.

Portes, Alejandro (2001), Legacies, Berkeley y Nueva York: University of California Press/Russell Sage Foundation.

Portes, Alejandro y Min Zhou (1993), "The Second Generation: Segmented Assimilation and its variants", en Annals of the American Academy of Political and Social Science, núm. 530, noviembre, Philadelphia: Sage Publications, pp. 74-96.

Rivera-Batiz, Francisco L. (2003), The state of newyorktitlan: a socioeconomic profile of mexican new yorkers, Nueva York: Columbia University.

Smith, Robert (2006), Mexican New York. Transnational Lives, Berkeley: California University Press.

Smith, Robert, Héctor R., Cordero-Guzmán y Ramón Grosfoguel (2001), Migration, Transnationalization and Race in a Changing NY, Philadelphia: Temple University Press.

Suárez-Orozco, Marcelo y Mariela Páez (eds.) (2002), Latinos Remaking America, Berkeley: University of California Press.

Valenzuela Arce, José Manuel (2009), El futuro ya fue: socioantropología de los jóvenes en la modernidad. Tijuana, México: El Colegio de la Frontera Norte/ Casa Juan Pablos.

Walzer, Michael (1993), Las esferas de la justicia. México: FCE.

Warner, W. Lloyd y Leo Srole (1945), The Social Systems of American Ethnic Groups, New Haven: Yale University Press.

Yashar, Deborah (2005), Contesting Citizenship in Latin America: The Rise of Indigenous Movements and the Post-Liberal Challenge, Cambridge: Cambridge University Press. 